\title{
INFLUENCE OF THE MIXING GRID POSITION ON THE COOLANT FLOW AT THE OUTFLOW PART OF THE NUCLEAR REACTOR FUEL ASSEMBLY PHYSICAL MODEL AND VALIDATION OF CFD MODEL
}

\begin{abstract}
In the year 2007 an experimental device with a physical model of the VVER 440 nuclear reactor fuel assembly was installed in the laboratory of The Institute of Power Engineering of the Faculty of Mechanical Engineering of the Slovak University of Technology in Bratislava. Within the framework of the reconstruction a third measuring plane was added to the original two, new combined probes were designed with temperature resistant sensors instead of the thermocouples, and piezoelectric pressure sensors for each probe were used. In this article we investigate the influence the mixing grid positioning has on smoothing the temperature profile in the fuel assembly outlet. The preliminary results of the ongoing validation of CFD simulations by means of experimental data are presented.
\end{abstract}

Keywords: Nuclear reactor, fuel assembly, physical model, mixing grid position, measurements, CFD, validation

\section{Introduction}

Coolant flows along a 126 fuel rod bundle in the VVER 440 nuclear reactor fuel assembly. During the nuclear reactor operation, the temperature fluctuation is irregular in each single fuel rod, depending on the fuel properties and the position of the fuel assembly in the reactor. In the fuel assembly outlet the coolant temperature profile is irregular. In the fuel assembly, at the point where the flow cross section changes from hexagonal to circular, a mixing grid, which flattens the coolant temperature profile, is located. Subsequently, the coolant flows through the fuel assembly outlet where the cross section shape and area change. The next step in smoothing the coolant temperature profile is performed by a catcher. Coolant temperature in the fuel assembly outlet is measured by a thermocouple located in the fuel assembly axis, and is positioned $300 \mathrm{~mm}$ from the end of the fuel rods (Fig. 1, plane 3). Measurements are provided at only one point. Safe and effective loading of nuclear reactor fuel assemblies demands qualitative and quantitative analysis of the relationship between the coolant temperature in the fuel assembly outlet, measured by the thermocouple, and the mean coolant temperature profile in the thermocouple plane position. It is not possible to perform the analysis directly in the reactor, so it is carried out using measurements on the physical model, and the CFD fuel assembly coolant flow models. The CFD models have to be verified and validated in line with the temperature and velocity profile obtained from the measurements of the cooling water flowing in the physical model of the fuel assembly.

\section{Experimental device with physical model of nuclear reactor fuel assembly}

In the laboratory of The Insitute of Thermal Power Engineering of the Slovak University of Technology in Bratislava, a physical experimental copy of the fuel assembly model of a VVER 440 nuclear power plant was installed. The model was created to a scale of 1:1.125. The measurements on the model were made with different water mass flow at four different positions of the mixing grid. The temperature and velocity profiles were measured with 2 combined probes located in 3 planes at the outlet of the fuel assembly in the physical model (Fig. 1):

- plane 1 is situated between the end of fuel rod boundle and mixing grid,

- plane 2 is situated behind the mixing grid and the end of central the tube at the begining of the cylindrical head of the fuel assembly outlet,

- plane 3 is positioned at the nuclear reactor fuel assembly thermocouple.

Knowing the relationship between experimentaly measured and CFD calculated coolant temperature at the fuel assembly outlet, and mean coolant temperature in the plane of thermocouple position is a necessary condition for safe and efective loading of nuclear reactor fuel assemblies.

Due to the fuel assembly model design, the water pressure, and the temperature during experiments, the velocity and temperature

\footnotetext{
* Frantisek Urban, Lubor Kucak, Jozef Bereznai, Marian Pulmann, Jozef Tihanyi

Institute of Power Engineering, Faculty of Mechanical Engineering of the Slovak University of Technology, Bratislava, Slovakia,

E-mail: frantisek.urban@stuba.sk
} 
profiles mesurements are taken near the automodelling flow region. The coefficient of friction $\lambda$ is constant, independent of the Reynolds number. The compliance between the size and physical dimensions of the fuel assembly model and the actual reactor fuel assembly is achieved by ensuring the results of measurements on the model correspond with the coolant flow in the real fuel assembly outlet [1].

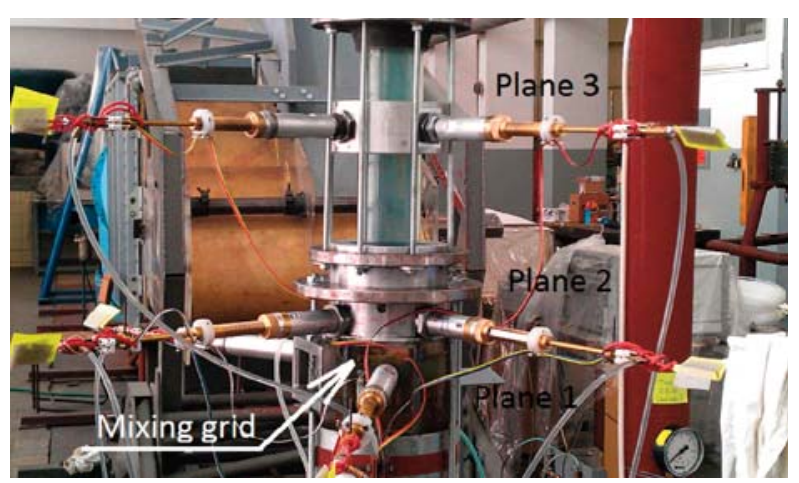

Fig. 1 Physical model of fuel assembly outlet with combined traverse probes devices located in planes 1, 2 and 3

In the plane of the fuel rod bundle ending, temperature discontinuity is modeled by mixing the heated (primary) water that is flowing along fuel rods bundle with cool (secondary) water flowing from one of the tube triplets $\alpha, \beta, \gamma$ with an outer diameter of $8 \mathrm{~mm}$ and an inner diameter of $5.6 \mathrm{~mm}$ (Figs. 2 and 3) and/or a central tube with outer and inner diameters of $10 \mathrm{~mm}$ and $8.5 \mathrm{~mm}$ respectively (Figs. 2 and 3). Temperature and velocity profiles are measured with the combined probes A1 a B1 located in plane 1 in the zone between the rod bundle end and the mixing grid. Plane 2 is located between the end of the central tube and the catcher, with combined probes A2 and B2. In plane 3, where the thermocouple for measuring outlet water temperature is located in the real fuel assembly, the traverse devices for combined probes A3

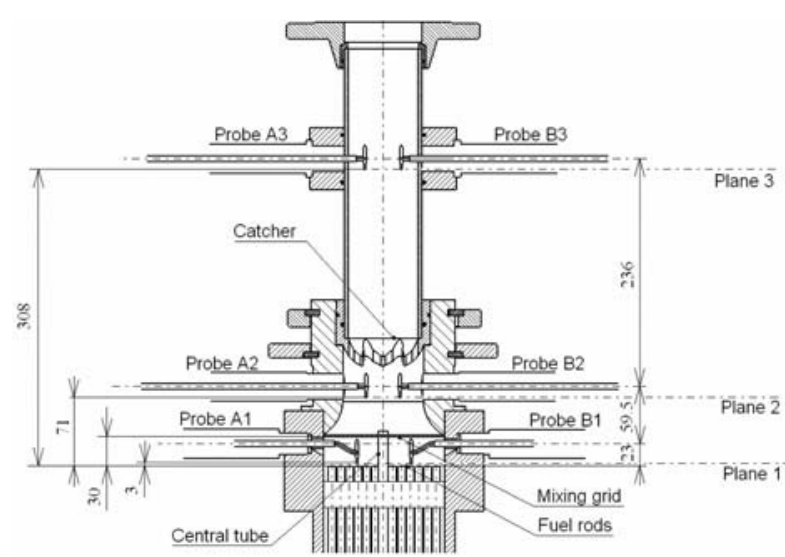

Fig. 2 Outlet of fuel assembly physical model with combined probes in the planes 1, 2 and 3 and $\mathrm{B} 3$ for temperature and velocity profile measurements are installed. At the outlet of the fuel assembly model, water flow mean temperature is measured with a Pt 100 thermometer.

It is possible to observe the mixing of the water flow through plexiglass walls, using coloured cool water mixed into the fuel assembly outlet through triplet tubes or a central tube.
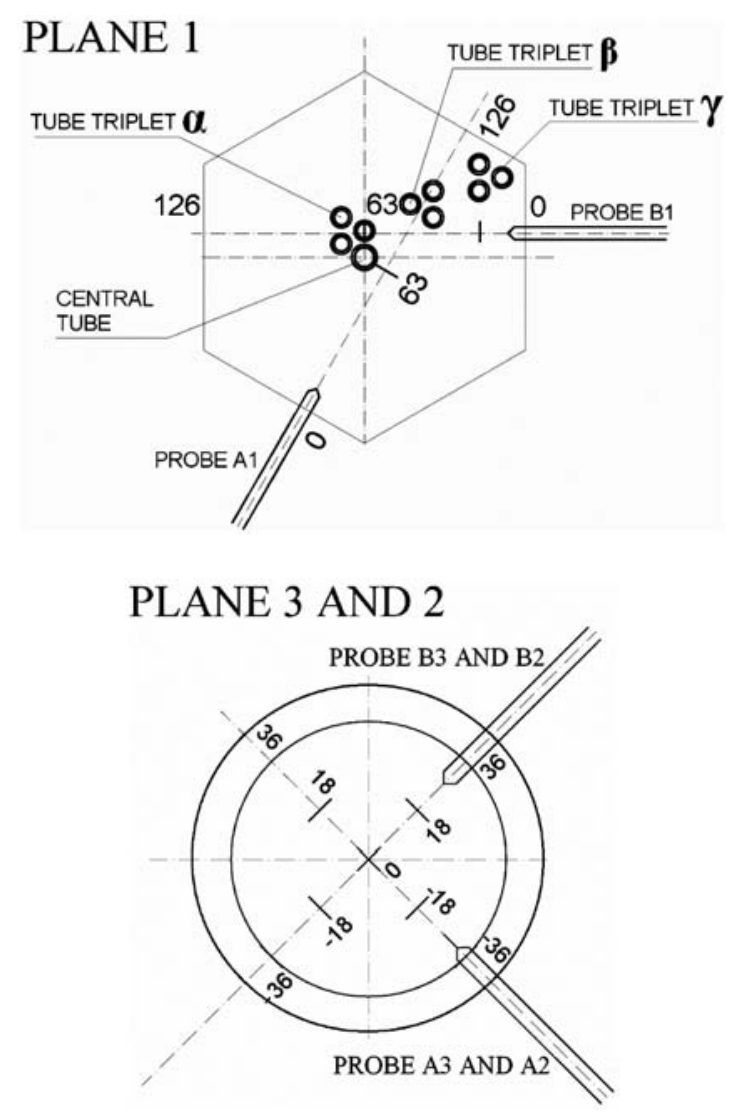

Fig. 3 Location of combined probes A1, B1 in plane 1 and probes A2, $B 2$ behind probes $A 3, B 3$ in plane 3

\section{Reconstruction of fuel assembly physical model}

To reduce uncertainties in temperature and velocity profile measurement of the water flow in the physical model fuel assembly outlet the reconstruction of the physical model of the fuel assembly was made to include new combined probes, and the measurement procedure was modified.

Water flowing through the reactor fuel assembly mixing grid perforation is mixed with cooler water flowing from the central tube. The physical model of the fuel assembly was modified in such a way that 2 new combined probes were placed after the mixing grid. In plane 2 (Fig. 2) temperature and velocity profile of water flowing 
between the mixing grid and the catcher is measured. This measurement adds information about the intensity of coolant mixing in the outlet of the fuel assembly model [2].

\subsection{Reconstruction of combined probes}

In original traversing combined probes for temperature and dynamic pressure measurement were above arc of Pitot probe neck placed tip of thermocouple (Fig. 5, up). In planes 1 and 3 of the fuel assembly physical model outlet, the dynamic pressures and temperatures were measured at an appropriate point.

In order to minimize uncertainties in the measurement of water temperature the thermocouples used in the original 4 probes were calibrated [3]. For the digital thermometer with thermoelectric temperature sensors of type $\mathrm{K}$, with a diameter of $1 \mathrm{~mm}$, the expanded uncertainty of temperature measurement was specified during the calibration. This expanded uncertainty of measurement of $1.10^{\circ} \mathrm{C}$ was specified according to TPM 0051-93 and is defined as the standard uncertainty multiplied by coverage factor $k=2$ (with $95 \%$ level of confidence). In view of the measured temperature values of flowing water in the fuel assembly physical model, the expanded uncertainty of $1.10^{\circ} \mathrm{C}$ of temperature measurement is too high. This was the reason for the reconstruction of the combined probes, whilst the thermocouples were replaced by miniature resistance thermometers Pt 100 which have a measured temperature deviation of $\pm 0.15^{\circ} \mathrm{C}[4]$.

Within the framework of the reconstruction, modification of the original probes and the production of 2 new combined probes with a miniature platinum thermometer was considered. The temperature sensor Pt 100 has a cylindrical shape with a diameter of $2 \mathrm{~mm}$ and a $7.6 \mathrm{~mm}$ length, with 4 wires. Installing the probe required changes to the combined probes design (Figs. 4 and 5 down).

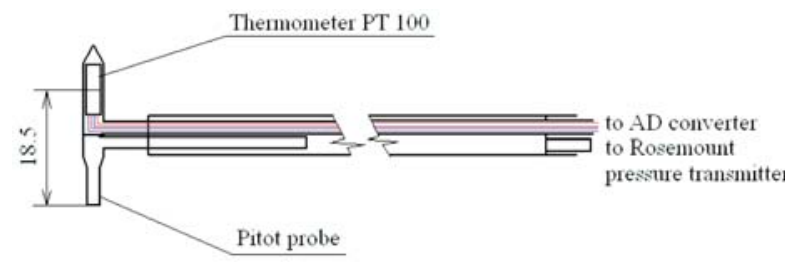

Fig. 4 Schematic sketch of new combined probe for temperature and velocity measurement

The Pitot probe is located in a bush, together with the Pt 100 thermometer (Fig. 5 to the left of probe 1B), but are separated within the bush. The miniature platinum thermometer cannot operate in water, thus it is placed in a brass bush. The new probe requires more space in the measurement zone as can be seen in Fig 5 .

For dynamic and static pressure measurement, the piezoelectric pressure sensors are used in Rosemount 2051 transmitters with

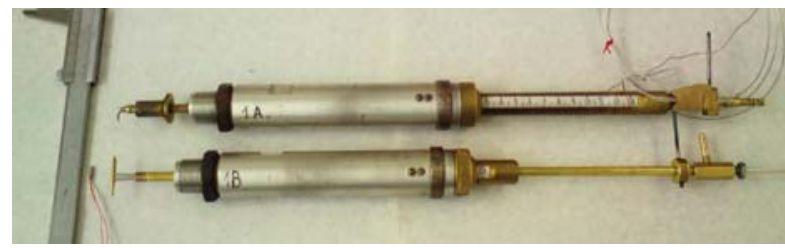

Fig. 5 Original combined probe with thermocouple (top) and new combined probe with bush for platinum thermometer (bottom)

a reference accuracy of $\pm 0.075 \%$ of voltage. In the last phase of reconstruction each of the 6 combined probes will be installed with an electromotor with appropriate gears to enable fully automized control of the traverse from a personal computer.

\section{Measurements by different configurations of mixing grid}

The mixing grid has significant influence on coolant mixing in the fuel assembly. It is situated $30 \mathrm{~mm}$ behind the plane of the fuel rod endings. The producer supplies the fuel assemblies with the mixing grid installed in two different positions and two more positions are possible by different placing of the assembly in the reactor active zone (Fig. 6). The influence of mixing grid position on water flow in the fuel assembly outlet is analysed in following section.

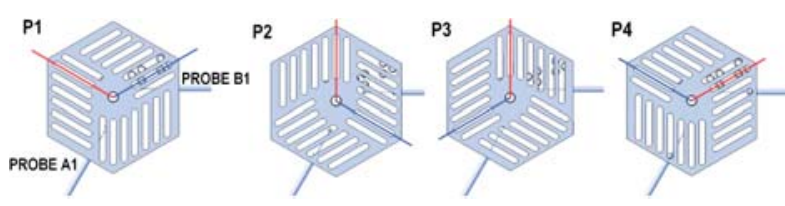

Fig. 6 Positions P1, P2, P3 a P4 of mixing grid in nuclear reactor fuel assembly

The results of measurements made using an isokinetic cold water supply delivered through the $\alpha$ triplet of tubes and a central tube are presented. The modelled water flow was measured using a Venturi meter in the mixing grid positions P1, P2, P3 and P4, within the range from $m_{\text {clona }}=11.12{\mathrm{~kg} . \mathrm{s}^{-1}}(\mathrm{P} 1)$ to $m_{\text {clona }}=$ $=11.14 \mathrm{~kg} \cdot \mathrm{s}^{-1}(\mathrm{P} 4)$. It was not possible in compared measurements, to keep the temperature of the water in a storage tank at the same level.

In Fig. 7, temperature profiles in plane 1 are illustrated for mixing grid positions $\mathrm{P} 1, \mathrm{P} 2, \mathrm{P} 3$ and $\mathrm{P} 4$. During traversing probe A1 was out of the flow of cool water, therefore the temperature decrease of the 1 1A_Px in the middle of the assembly is not significant. Probe B1 is measuring the temperature $\mathrm{t}$ 1B_Px in the middle of the assembly influenced by cold water flow through triplet tubes $\alpha$ (Fig. 7, $x=72 \mathrm{~mm}$ ). Differences between water temperatures $t_{\max }-t_{\min }$ in plane 1 are from $4.50^{\circ} \mathrm{C}$ (position of mixing grid $\mathrm{P} 2$ ) to $5.60{ }^{\circ} \mathrm{C}(\mathrm{P} 1)$. 


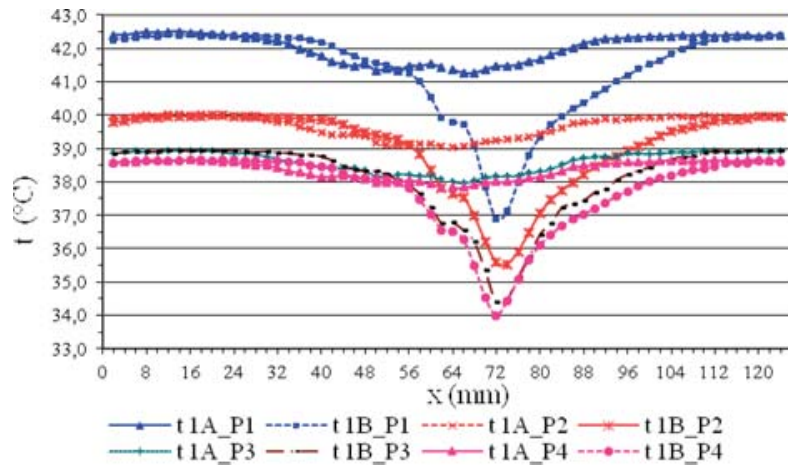

Fig. 7 Temperature profiles in plane 1 for mixing grid position $P 1, P 2, P 3$ a P4

In plane 2 the temperature profile is smoothed in the periphery of the cross section as a result of the influence of the mixing grid (Fig. 8). The temperature profile is significantly influenced by cool water input from the central tube. Differences of water temperature $t_{\max }-t_{\min }$ in plane 2 are from $3.20{ }^{\circ} \mathrm{C}(\mathrm{P} 3)$ to $3.92{ }^{\circ} \mathrm{C}$ (P1).

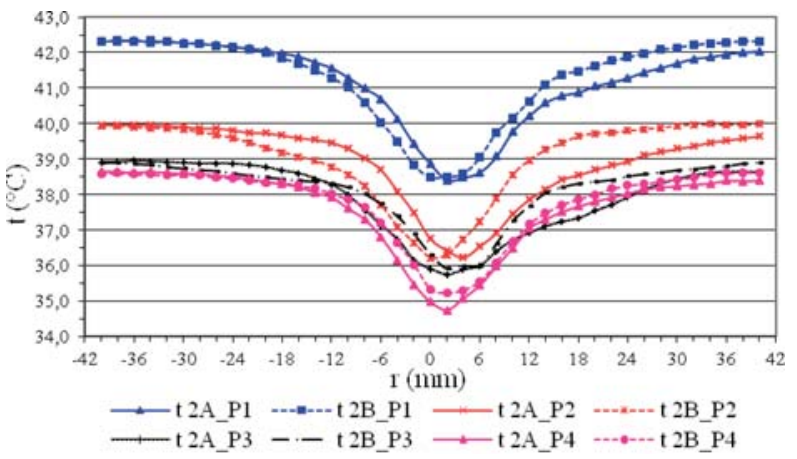

Fig. 8 Temperature profiles in plane 2 for mixing grid position P1, P2, P3 a P4

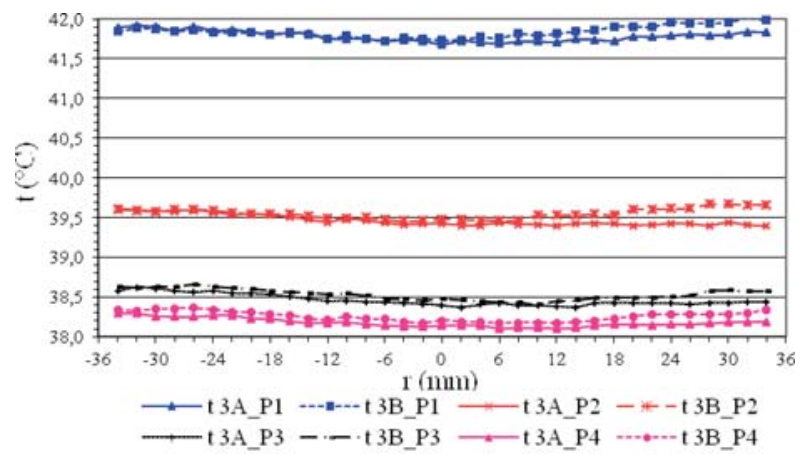

Fig. 9 Temperature profiles in plane 3 for mixing grid position P1, P2, P3 a P4
During water flow between planes 2 and 3 turbulence around the catcher causes another smoothing of the temperature profile in plane 3 - the plane where the thermocouple in the real fuel assembly is positioned (Fig. 9). Differences in water temperatures $t_{\max }-t_{\text {min }}$ in plane 3 are from $0.15{ }^{\circ} \mathrm{C}(\mathrm{P} 4)$ to $0.33{ }^{\circ} \mathrm{C}(\mathrm{P} 1)$.

\section{Validation of CFD fuel assembly model}

The CFD simulations of the fuel assembly model have to be validated and verified for the purpose of further computational analysis. The objective is to achieve the maximum accuracy of the CFD simulations compared to real-time experiments. Hence suitable computational mathematical models were sought which would represent the physical phenomena of the experiment with minimal deviations.

With CFD model (Fig. 10) an analysis of three different, unstructured meshes was made: a coarse mesh grid with approximately 200000 elements; a medium grid with 750000 elements; and a fine grid with 2000000 elements (Fig. 11). An adiabatic wall, with velocity inlet boundary condition and with pressure outlet boundary condition was used for the simulations.

For better correspondence of CFD simulations with the experiment, 4 mathematical turbulence models were tested - standard k-

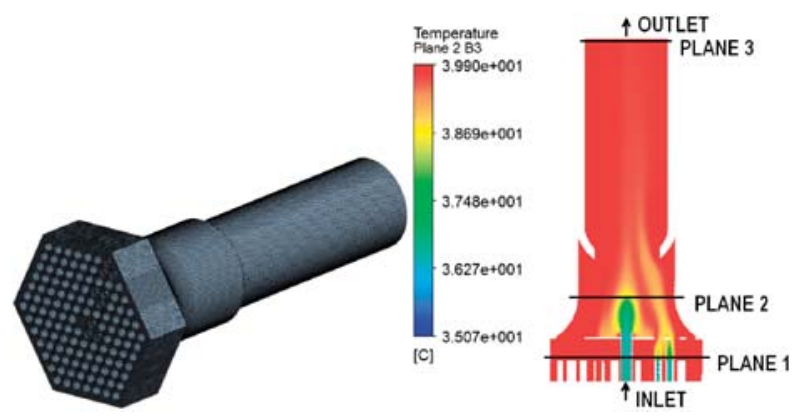

Fig. 10 Computational grid and temperature profile along cut of fuel assembly outlet

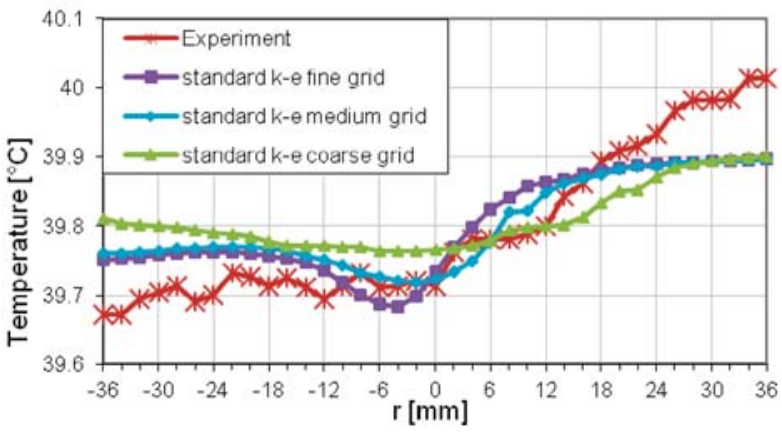

Fig. 11 Meshing grid comparison with calculated temperature profiles in plane 3 of fuel assembly outlet 


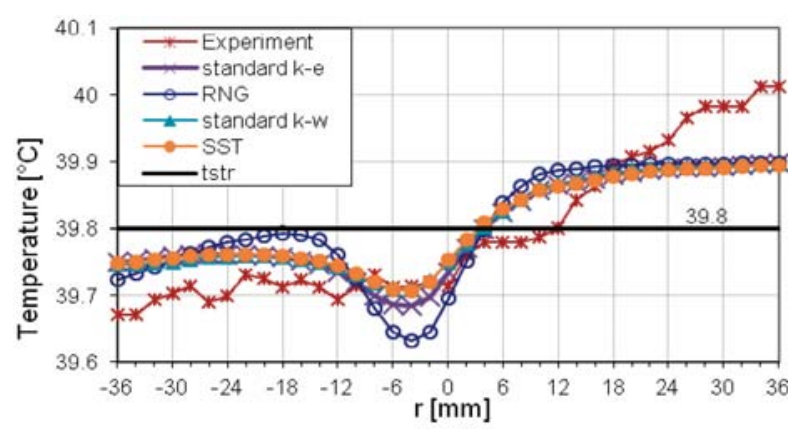

Fig. 12 Turbulence model comparison with calculated temperature profiles in plane 3 of fuel assembly

$\varepsilon$, RNG k- $\varepsilon$, standard $k-\omega$ and SST $k-\omega$ using the fine mesh (Fig. 12).

The results show large variations at the center of the cross section, with the standard k- $\omega$ and SST k- $\omega$ models matching the measured data more closely than the RNG model which showed a higher temperature drop at the center of the cross section. The greatest difference between the measured values is $0.34^{\circ} \mathrm{C}$, and the difference between the calculated temperature values of the SST model is $0.20^{\circ} \mathrm{C}$. The turbulence models were unable to match the temperature increase in the last phase of probe traversation where the difference between the measured and calculated values is $0.11^{\circ} \mathrm{C}$. Temperature difference between SST and RNG turbulence models and the calculated mean temperature $t_{s t r}$ at the position where the thermocouple is positioned in the reactor fuel assembly (Fig. 12, $r=-4 \mathrm{~mm}$ ), is $0.08^{\circ} \mathrm{C}$.

An analysis of the influence of the inlet boundary turbulence intensity shows no effect on the temperature profile in the fuel assembly outlet.

\section{Conclusion}

The third measurement plane that was added in the reconstruction of the VVER 440 nuclear reactor fuel assembly physical model gives us better information about the influence of the central tube coolant flow on the temperature profile in the plane of thermocouple postion in the real fuel assembly (plane 3 on fuel assembly model). Reducing the uncertainties of the measured temperature values was achieved by replacing the thermocouples in the combined probes with a miniature platinum thermometer, and dynamic pressures are measured with pressure transmitters separately for each probe.

The presented results of measurements carried out with isokinetic cold water input through $\alpha$ triplet tube and central tube and water flow for mixing grid positions $\mathrm{P} 1, \mathrm{P} 2, \mathrm{P} 3$ and $\mathrm{P} 4$ within the range from $m_{\text {clona }}=11.12 \mathrm{~kg} . \mathrm{s}^{-1}(\mathrm{P} 1)$ to $m_{\text {clona }}=11.14 \mathrm{~kg} \cdot \mathrm{s}^{-1}$ (P4). In the plane of the real fuel assembly thermocouple position - plane 3 of the physical model fuel assembly - the differences between water temperature $t_{3 A}(\mathrm{r}=0), t_{3 B}(\mathrm{r}=0)$ measured with resistor thermometers at the position of the combined probes A3 and $\mathrm{B} 3$ at point $\mathrm{r}=0 \mathrm{~mm}$ and calculated temperature $t_{\text {str } 3}$ is between $0.05{ }^{\circ} \mathrm{C}$ for mixing grid position $\mathrm{P} 3$ and $\mathrm{P} 4$, and $0.17^{\circ} \mathrm{C}$ for mixing grid position $\mathrm{P} 1$. Differences of temperature values are within the range of temperature measurement uncertainty measured with the resistor thermometer. The mixing grid position influences the temperature profile in plane 3 only insignificantly.

So far, from the acquired data of the CFD simulations validation we can conclude that turbulence intensity change at the inlet boundary condition has minimal influence on the outlet temperature profile. Furthermore, on the evidence of the turbulence models tested, the $k$ - $\omega$ models match the experimental data more closely than the $k-\omega$ models. The next step will be to focus more on investigating the size of the time steps, type and quality of mesh, inlet boundary conditions, and other turbulence models.

\section{Acknowledgements}

Preparation of this paper was supported by the Research and Development Operational Programme of the European Union's ERDF through the Centre of Competence in New Materials, Advanced Technologies and energy project, ITMS 26240220073.

\section{References}

[1] MUSKAT, P., URBAN, F., PULMANN, M.: Merania na fyzikalnom modeli palivoveho clanku jadroveho reaktora [Measurements on the Physical Model of Nuclear Reactor Fuel Assembly]. Strojnicky casopis = Journal of Mechanical Eng., 2008, vol. 5-6, No. 59, pp. 305-315 ISSN 0039-2472.

[2] BEREZNAI, J.: Termokineticka a hydraulicka analyza prudenia chladiva v jadrovom reaktore VVER 440 [Thermokinetic and Hydraulic Analysis of the Coolant Flow in the Nuclear Reactor VVER 440]. Dissertation thesis. Bratislava, 2010, 58 p.

[3] SLANINA, M., REPA, M., CAPUSKA, J.: Odovzdavaci protokol. Certifikat o kalibracii c. 42/2009 az c. 45/2009 [Handover Protocol. Certificate of the Calibration no. 42/2009 to no. 45/2009]. VUJE, a.s. Trnava. Akreditovane kalibracne laboratorium teploty. Trnava, 29.12.2009.

[4] CHUDY, V., PALENCAR, R., KUREKOVA, E., HALAJ, M.: Meranie technickych velicin [Measurement of Technical Quantities]. STU, 1999, ISBN 80-227-1275-2. 